\title{
轴手性芳基烯烃-吲哚骨架的设计和催化不对称构建
}

\author{
谭 斌* \\ (南方科技大学化学系 广东深圳 518055)
}

\section{Design and Catalytic Asymmetric Construction of Axially Chiral Aryl-Alkene-Indole Frameworks}

Tan, Bin*

(Department of Chemistry, Southern University of Science and Technology, Shenzhen, Guangdong 518055)

轴手性芳环骨架是众多天然产物、优势手性配体和 催化剂的核心结构单元, 其高对映选择性构建引起了有 机合成化学家的广泛关注. 近年来, 在这类优势轴手性 骨架导向的不对称有机小分子催化领域取得了突飞猛 进的进展 ${ }^{[1]}$. 其中, 关于轴手性六元联二芳环以及轴手 性五元杂芳环骨架的催化不对称构建的进展尤为突 出 $^{[1,2]}$, 该类骨架已发展成为轴手性芳环大家族的中坚 力量. 但是, 与之形成鲜明对比的是, 轴手性烯烃-芳环 骨架作为一类新型的阻旋异构大家族的成员, 其催化不 对称构建却发展缓慢, 主要原因是轴手性烯烃-芳环骨 架的构建中存在许多挑战. 例如手性轴的旋转能垒低、 构型稳定性弱、Z/E 选择性和对映选择性难以控制等. 2017 年我们课题组 ${ }^{[3]}$ 采用手性二级胺催化的炔烃官能 化反应首次实现了轴手性烯烃的不对称合成. 为了进一 步解决这些挑战性问题, 合成化学工作者们发展了一类 有机催化下乙烯基邻亚甲基苯醌(VQMs)参与的反应, 实现了一系列轴手性烯烃的对映选择性构建 ${ }^{[4,5]}$. 尽管 如此, 轴手性烯烃一杂芳环骨架的催化不对称构建却一 直没有报道. 相比之下, 该类骨架中兼具轴手性烯烃和 轴手性五元杂芳环两种构型相对不稳定的结构单元, 因 此其催化不对称构建更具挑战性. 在这种形式下, 非常 有必要设计新型的轴手性烯烃-杂芳环骨架并开发其催 化不对称构建策略.

近年来, 含有吲哚母核的轴手性骨架的催化不对称 构建已成为一个新兴的研究领域. 例如, 2010 年 Kitagawa 课题组 ${ }^{[6]}$ 实现了第一例具有 $\mathrm{C}-\mathrm{N}$ 手性轴的 $N$ 芳基吲哚骨架的催化不对称构建. 2017 年和 2018 年, 石 枫课题组 ${ }^{[7]}$ 和我们课题组 ${ }^{[8]}$ 分别实现了具有 $\mathrm{C}-\mathrm{C}$ 手性
轴的 3-芳基吲哚骨架的有机催化不对称构建. 2019 年, 石枫课题组 ${ }^{[9]}$ 开创性地完成了具有 $\mathrm{C}-\mathrm{C}$ 轴手性的 3,3'双吲哚骨架的高对映选择性构建. 这些研究工作表明, 吲哚可以作为构建轴手性骨架的一类优势杂芳环.

在这些研究工作基础之上, 最近, 石枫课题组 ${ }^{[10]}$ 设 计了一类新型的轴手性烯烃-杂芳环骨架——烯烃-吲 哚骨架, 并借助于有机催化完成了它的不对称构建. 设 计思路如下: 在手性布朗斯特酸 $(\mathrm{B} *-\mathrm{H})$ 催化下, 3 -炔基2-吲哚甲醇可以作为 1,4-双亲电试剂, 接受具有两个亲 核反应位点试剂的进攻, 发生催化不对称 $[4+n]$ 环化反 应. 由于新生成的双键末端的大位阻基团与吲哚环 C-4 氢原子之间存在空间位阻, 同时新形成的环会使烯烃和 吲哚之间的 $\mathrm{C}-\mathrm{C}$ 轴旋转受阻, 所以可以形成具有较稳 定构型的轴手性烯烃-吲哚骨架(Scheme 1).

在此思路指引之下, 石枫课题组设计了手性磷酸 (CPA) 催化下 3-炔基-2-吲哚甲醇与 2-荎酚或苯酚的不对

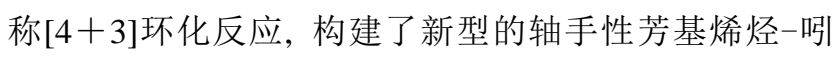
哚骨架，同时还构建了吲哚并七元含氧杂环骨架，获得 了高的收率、优秀的 Z/E 选择性和对映选择性(Scheme 2). 为了阐明反应的可能机理, 该课题组联合湖南科技 大学的焦银春课题组, 对两种可能的反应历程进行了理 论计算. 结果发现, 3-炔基-2-吲哚甲醇在手性磷酸催化 下, 可以转变为一种新型的手性联烯一亚胺中间体并接 受亲核试剂的进攻, 发生联烯轴手性到烯烃一吲哚轴手 性的转移, 然后通过分子内环化构建了轴手性芳基烯 烃一吲哚骨架. 新型联烯一亚胺反应中间体的发现将为后 续研究 3-炔基-2-吲哚甲醇参与的化学反应提供理论依 据.

* Corresponding author. E-mail: tanb@sustech.edu.cn. Published online April 13, 2020. 


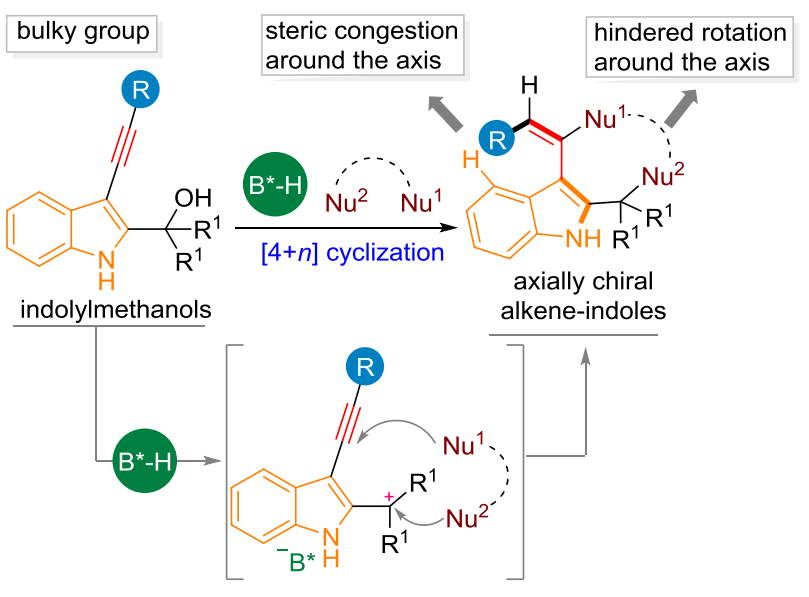

图式 1 催化不对称构建轴手性烯烃-吲哚骨架的策略

Scheme 1 Strategy for catalytic asymmetric construction of axially chiral alkene-indole frameworks

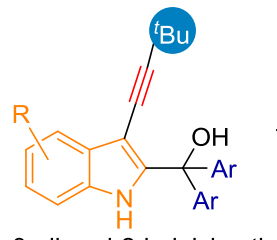

3-alkynyl-2-indolylmethanols

CPA 1st nucleophilic addition

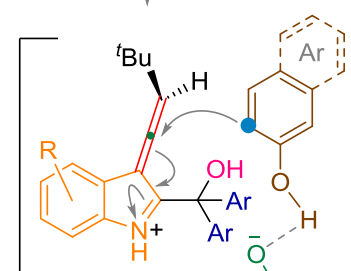

allene-iminium
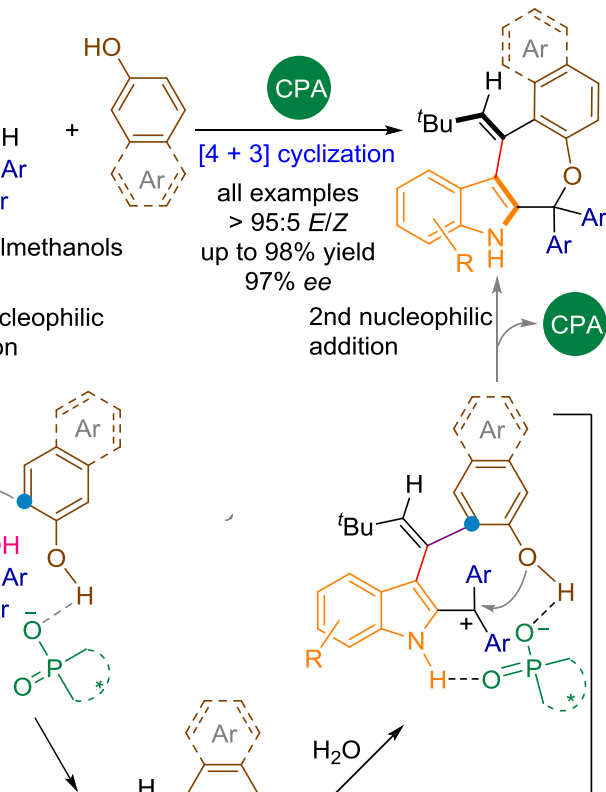
up to $98 \%$ yield $97 \%$ ee 2nd nucl
addition
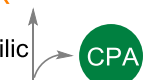$$
\text { Cand }
$$
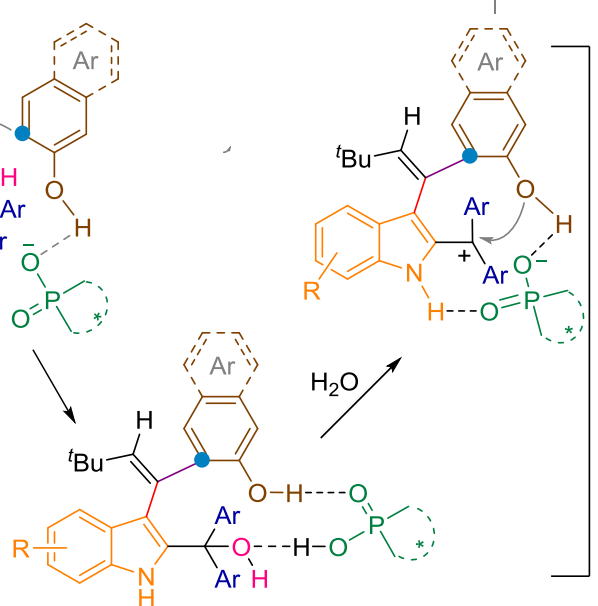

图式 2 构建轴手性烯烃-吲哚骨架的催化不对称[4+3]环化 反应

Scheme 2 Catalytic asymmetric [4+3] cyclization for constructing axially chiral alkene-indole frameworks

为了考察该类轴手性骨架的稳定性, 作者通过消旋
化实验计算出代表性化合物的旋转能垒为 $117 \mathrm{~kJ} \cdot \mathrm{mol}^{-1}$ (图 1a)，略高于室温下能分离出阻旋异构体所需的能垒 $\left(100 \mathrm{~kJ} \cdot \mathrm{mol}^{-1}\right)$, 这验证了催化不对称构建轴手性烯 烃吲哚骨架的挑战性，同时也说明了该策略在催化不对称 构建轴手性烯烃-吲哚骨架中的优势。此外，通过对这 类轴手性产物的细胞毒活性测试, 发现了一种对多种肿 瘤细胞具有显著的细胞毒活性的结构(图 1b), 相关研究 将为该类轴手性化合物在生物活性篮选中的应用打下 基础. (a)

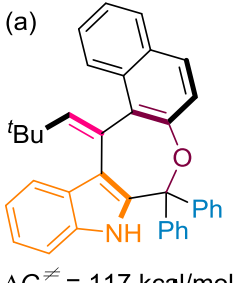

$\left(60{ }^{\circ} \mathrm{C},{ }^{i} \mathrm{PrOH}\right)$

Racemization barrier

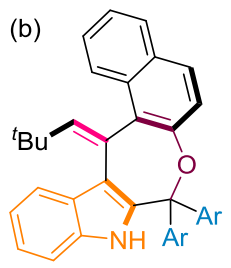

$\mathrm{Ar}=4-\mathrm{FC}_{6} \mathrm{H}_{4}$

Cytotoxic to MCF-7, MKN-45,

BGC-823, ECA-109

cancer cell lines
图 1 轴手性烯烃-吲哚骨架的消旋化能垒和细胞毒活性

Figure 1 Racemization barrier and cytotoxicity of axially chiral alkene-indole frameworks

总而言之，该工作实现了新型轴手性芳基烯烃-吲 哚骨架的催化不对称构建, 为阻旋异构家族增添了新的 成员，也为轴手性烯烃一杂芳环骨架的催化不对称构建 提供了新颖的策略.

\section{References}

[1] Wang, Y.-B.; Tan, B. Acc. Chem. Res. 2018, 51, 534.

[2] Zhang, S.; Liao, G.; Shi, B.-F. Chin. J. Org. Chem. 2019, 39, 1522 (in Chinese).

(张硕，廖港，史炳锋，有机化学, 2019, 39, 1522.)

[3] Zheng, S.-C.; Wu, S.; Zhou, Q.; Chung, L. W.; Ye, L.; Tan, B. Nat. Commun. 2017, 8, 15238.

[4] Jia, S.; Chen, Z.; Zhang, N.; Tan, Y.; Liu, Y.; Deng, J.; Yan, H. J. Am. Chem. Soc. 2018, 140, 7056.

[5] Wang, Y.-B.; Yu, P.; Zhou, Z.-P.; Zhang, J.; Wang, J.; Luo, S.-H.; Gu, Q.-S.; Houk, K. N.; Tan, B. Nat. Catal. 2019, 2, 504.

[6] Ototake, N.; Morimoto, Y.; Mokuya, A.; Fukaya, H.; Shida, Y.; Kitagawa, O. Chem.-Eur. J. 2010, 16, 6752

[7] Zhang, H.-H.; Wang, C.-S.; Li, C.; Mei, G.-J.; Li, Y.; Shi, F. Angew. Chem., Int. Ed. 2017, 56, 116.

[8] Qi, L.-W.; Mao, J.-H.; Zhang, J.; Tan, B. Nat. Chem. 2018, 10, 58.

[9] Ma, C.; Jiang, F.; Sheng, F.-T.; Jiao, Y.; Mei, G.-J.; Shi, F. Angew. Chem., Int. Ed. 2019, 58, 3014

[10] Wang, C.-S.; Li, T.-Z.; Liu, S.-J.; Zhang, Y.-C.; Deng, S.; Jiao, Y.; Shi, F. Chin. J. Chem. 2020, 38, 543. 